\title{
MUTUAL COUPLING BETWEEN HORIZONTAL EARTH RETURN CONDUCTORS USING ACTUAL ROUTING PARAMETERS
}

\author{
Eldon J. Rogers, L.S. Member, IEEE \\ Consulting Electrical Engineer
}

\author{
John F. White, Member, IEEE \\ Electrical Engineer
}

Bonneville Power Administration, MKTP

P.O. Box 491 Vancouver, Washington, 98666

Abstract Formula for calculating mutual coupling between diversely routed, horizontal earth-return conductors used in the measurement of grounding system impedance is derived by using the complex ground plane concept used to approximate the Carson Equation. Each potential conductor section is approximated with equal length segments that parallel one of the current conductor sections. By repeating the parallel segmentation of each potential conductor section with each subsequent current conductor section and summing the segment mutuals, overall mutual betwoen diversely routod conductors is obtained. This process is useful for calculating mutual to the potential conductor and for comparing possible potential conductor routings so as to minimize the overall mutual coupling.

KEYVORDS: MUTUAL IMPEDANCE. FINITE LENGTH CONDUCTORS, EARTH RETURN, GROUNDING IMPEDANCE, GROUNDING SYSTEMS

\section{ITPODUCTIOA}

Impedance measurements of grounding grids and grounding systems require the use of temporarily installed conductors tying on ground, out-of-service transmission lines, or a combination of the two for connecting between the test grid and remote current and potential electrodes [II.

Because of constraints imposed by terrain, right-of-avays, roads, energized lines, and private property boundaries, it is unlikely, except for the smallest grids, that tost leads (or transmission lines) will be routed in either a parallel or angled simple straight line manner. As described in Ref. [1], mutual coupling from the current carrying conductor to the conductor used to measure grounding potential rise could introduce significant errors in the grounding impedance measurement. Moreover, accuracy of measurement for low impedance grounding systems vill require keeping the length of closely paralleled sections of current and potential conductors to a minimum.

Presently, mutual coupling from current to potential, for complex routing, can only be estimated from straight line approximations of their overall routing. In this paper we extend the segmented method for mutual coupling between angled conductors (using the complex ground return plane [1]), to diverse routings of horizontal conductors. Then, mutual impedance to the potential conductor, for a given routing of the current conductor can be minimized by comparing mutual couplings for several accessible potential conductor routings.

Mutuals calculated vith formules presented here are accurate for the direct component between conductors. Overall mutuals, as affected by the image component, fall below Carson for the vider spacing of very long parallel conductors [I].

90 Wh 057-0 PWRD A paper recommended and approved by the IEER Power System Instrumentation \& Weasurements Comittee of the IHSE Power Engineering Society for presentation at the IETE/PIS 1990 winter feeting Atlanta, Georgia, February $4-8,1990$. Kanuscript subritted Ausust 24, 1989 made available for printing January $16,1990$.

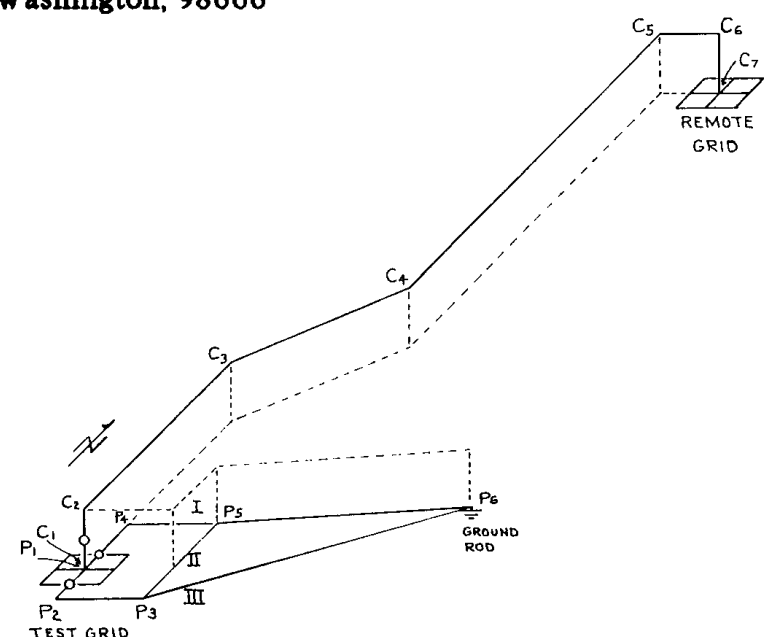

Figure 1 ROITING COORDINATHS FOR FACH CIRREANT AND POTIITIALCONDUCTORSECTION

\begin{tabular}{|c|c|c|c|c|c|c|c|}
\hline \multicolumn{4}{|c|}{ CURRENT } & \multicolumn{4}{|c|}{ POTENTIAL } \\
\hline LOC & $A_{r}$ & $\mathrm{~B}_{\mathrm{r}}$ & hc & Lac & $\mathbf{a}_{\mathbf{i}}$ & $b_{i}$ & hp \\
\hline$c_{1}$ & 0 & 0 & 0 & $P_{1}$ & 0 & 0 & 0 \\
\hline$C_{2}$ & 0 & 0 & 10 & $P_{2}$ & 0 & -250 & 0 \\
\hline$C_{3}$ & 0 & 1000 & 10 & $P_{3}$ & 300 & -250 & 0 \\
\hline$c_{4}$ & 400 & 1500 & 10 & $P_{4}$ & 0 & 500 & 0 \\
\hline$C_{5}$ & 400 & 10000 & 10 & $P_{5}$ & 300 & 500 & o \\
\hline$c_{6}$ & 700 & 10000 & 10 & $\mathbf{P}_{6}$ & 2000 & 650 & 0 \\
\hline$C_{7}$ & 700 & 10000 & 0 & & & & \\
\hline
\end{tabular}

$\mathrm{X}, \mathrm{Y}, \mathrm{Z}$ coordinates in meter

Formulas used to determine the mutual impedance from image conductors will require the evaluation of logarithms and square roots of complex numbers.

\section{COTICTOR ROITIIES}

Current and Potential conductor routings, shown in Fig. 1. demonstraces the diverse routings or a out-or-service uransmission line connecting between the test grid and the remote grid which acts as the current electrode, and three possible routings of a test conductor. lying on the earth, which vould connect between the test grid and a ground rod used as the remote potential electrode.

The relationship from any current section to each potential section may be parallel, angular and/or right angles. However, the mutual coupling analysis is aided by using a XYZ coordinate system to define change of direction locations of each current and potential section and their respective heights. The X-Y plane lies on the earth's surface and coordinate $Z$ = hC or hp are current and potential conductor heights, respectively.

Equations (9,12 and 14 or 15,16 and 18) of the Appendix use the $X-Y$ coordinates that define the routing of current and potential conductors to determine the mutual impedance between horizontal earth return conductors. Equations (22,24 and 25) of the Appendix are used for angled conductors that can be defined by their length. horizontal angle, and when both originate from a common vertical aris.

U.S. Government work not protected by U.S. copyright. 0885-8977/90/0700-1266\$01.00 @ 1990 IEEE 

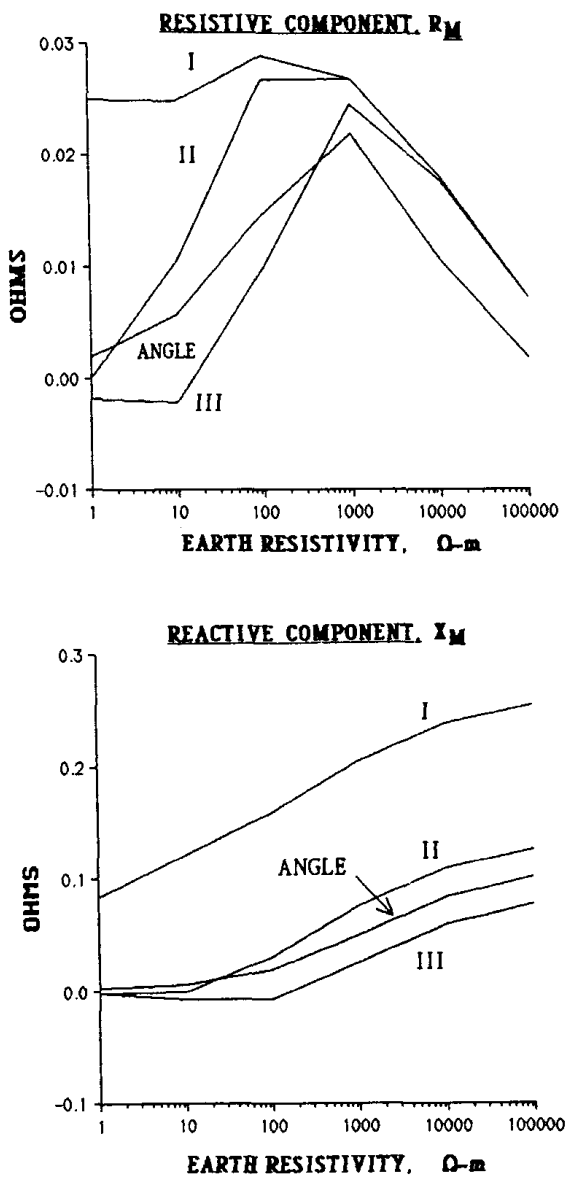

Figure 2 COMPARISON OF MUTUAL IMPEDANCE FOR THREE POTENTIAL CONDUCTOR ROUTINGS OF FIG I VITH AN ANGLED ROUTING

$I=P_{1}$ to $P_{4}$ to $P_{5}$ to $P_{6}$

II $=P_{1}$ to $P_{2}$ to $P_{3}$ to $P_{5}$ to $P_{6}$

III $=P_{1}$ to $P_{2}$ to $P_{3}$ to $P_{6}$

ANGLE $=$ CUR: $C_{2}$ to $C_{6} . \quad$ POT: $P_{1}$ to $P_{6}$
$f=60 \mathrm{~Hz}$
$\mathrm{C}=10024.5$

$$
P . .=2103
$$
$\theta=68^{\circ}$

\section{MUTUAL IMPEDAKCE VERSUS POTEMTIAL ROUTINGS}

Mutual impedance between the transmission line current conductor and each of the three potential conductor routings (I. II III) of Fig. 1 are compared in Fig. 2 with a fictitious straight line angled routing from $\mathrm{C}_{2}$ to $\mathrm{C}_{6}$ for the current and from $\mathrm{P} 1$ to $\mathrm{P} 6$ for the potential. Their mutual impedance components, $R_{M}$ and $X_{M}$, calculated with Eqs. (9,12 and 14 or 15, 16 and 18) of the Appendix are plotted in Fig. 2 against homogeneous earth resistivities of 1 to $100,000 \mathrm{n}-\mathrm{m}$.

Potential conductor routings, I and II, which lie closer to the current conductor have mutual components that are larger than for the fictitious angled routing. Routing III which is farthest from the current conductor has components that fall below the angled case. The magnitude of mutual impedance for routings II and III are reduced by the negative mutual coupling to the conductor section P1 to P2. Although there are many constraints that limit conductor routings, routing selection for minimum mutual coupling can be aided by prior study.

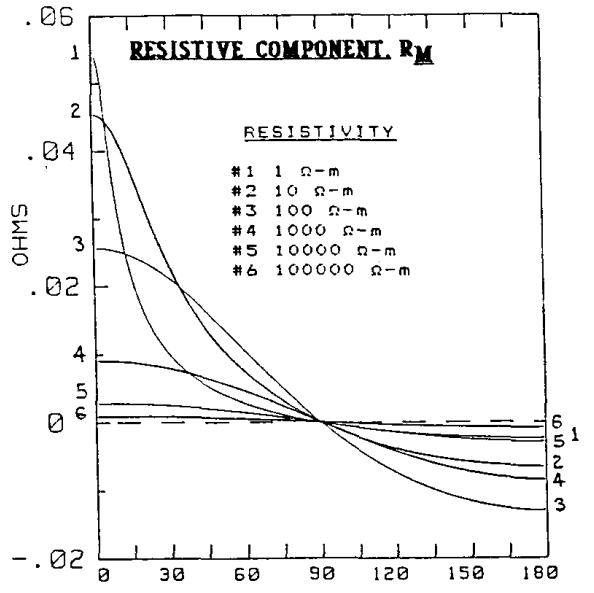

ANGLE BETWEEN CONDUCTORS

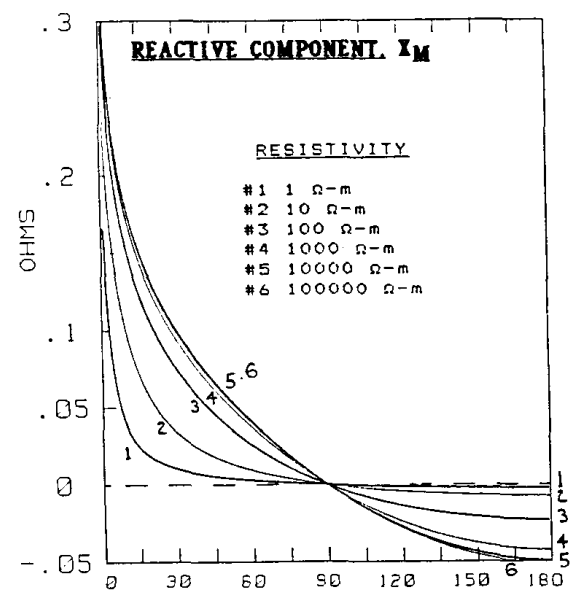

FNGLE BETWEEN CONDUCTORS

Figure 3 MUTUAL IMPEDANCE BET WEEN ANGLED CONDUCTORS $f=60 \mathrm{~Hz}, C=P=1 \mathrm{~km}, h_{C}=10 \mathrm{~m}, \mathrm{hp}=0 \mathrm{~m}$

OUTUAL IMPEDANCE BET EEN AMGLED CONUCTORS

When it is possible to route test conductors radially from the grid in a straight line, mutual coupling between angle conductors can be determined with Eqs. $(22,24$ and 25) of the Appendix. Fig. 3 shows the mutual impedance component variations of two $1 \mathrm{~km}$ long conductors for angle orientations $0^{\circ}<\theta<180^{\circ}$ and six homogeneous earth resistivities, 1 to $100,000 \Omega-m$. As earth resistivity increases the resistive component. $R_{M}$. decreases and the reactive component, $Z_{M}$, increases. Preferred angle is $90^{\circ}$, hovever, orientations from $60^{\circ}$ to $120^{\circ}$ vill have very small mutual impedan ce components. Orientation angles $120^{\circ}$ to $180^{\circ}$ have much smaller mutual components than those of $0^{\circ}$ to $60^{\circ}$

Equations (22, 24 and 25) of the Appendix give results that agree with the segmented summation method of Reference [1] Eqs. [19, 20 and 21$]$ and the segmented summation method of this paper. Eqs. (9, 12 and 14 or 15,16 and 18) of the Appendix. 


\section{CONCLUSIOHS}

1. Mutual impeaance Detween norizontal earth return conquctors with any orientation can be determined by the segmented method and Eqs. (9,12 and 14 or 15,16 and 18) of the Appendix.

2. Formulae presented in the paper are based on homogeneous earth, however, approximating heterogeneous earth is not critical as large variations in earth resistivity result in smaller changes in the resistive and reactive components of mutual impedance.

3 . The segmented method for diversely routed conductors is adaptable to the programmable hand calculator.

4. Negative mutual impedance of an initial potential section oriented $180^{\circ}$ with an initial current section is useful for reducing overall mutual coupling.

\section{REFERFNCES}

(1) E. J. Rogers and J. F. White. "Mutual Coupling between Finite Lengths of Parallel or Angled Horizontal Earth Return Conductors" IEEE Transactions on Power Delivery. Vol. 4, No 1, Jan. 1989, p.p. 103-113.

12] F.W. Grover, "Inductance Calculations: Working Formulas and Tables", Dover Publishing Co., N.Y., N.Y.. 1946, p.p. 8 and $55-57$

Eldon J Rogers (S'38,M'55,SM'62,LSM'82) was born in Edmonton Alberta Canada. He received the BSEE Degree from Oregon State University, Corvallis, Oregon in 1941

Except for service overseas as a 1st Lt. Army Signal Corp during WWII he worked for Bonneville Power Administration from 1941 until his retirement in 1983. Presently, he is working as a consultant for BPA providing expertise on testing. grounding. EMI reduction and partial discharge measurements He has authored or cD-authored papers on surge impedance, RN. LVI. EM1 Grounding. Measurement Techniques, and Mutual Impedance between Earth Return Conductors.

Mr. Rogers is a member of the WG producing IEEE Measurement Guide 81, Part 2 and a Registered Professional Engineer (retired) in the State of Oregon

John F. White (S71, M'73) was born in Oregon City. Oregon. June 23. 1950. Received a BS. Degree from Portland State University in 1972 in Electrical Engineering.

He joined the Bonneville Power Administration in 1973 as a Test Engineer for the Branch of Test and Energization. Since 1979 he has been involved with Special Test Projects, test procedures and equipment testing. He is a member of BPA's Committees on Grounding. GIS ,EMI and PCB's. He has co-authored papers on Grounding and Mutual Impedance between Earth Return Conductors

Mr. White is a member of the $W G$ producing IEEF Measurement Guide 81 Part 2 and a Registered Professional Engineer in the State of Oregon

\section{APPENDIX}

\section{A 1 MUTUAL COUPLING FOR DIVERSE CONDUCTOR ROUTINGS}

The Coordinate System Determining the mutual coupling between diversely routed conductors such as Fig 1, requires establishing a reference location for a $X-Y$ coordinate system. Any convenient location on the grid can be selected and the $X-Y$ coordinates determined for the measuring point on the grid the end points of each current section and the end points of each potential section In the Fig. 1 example, the measuring point on the grid is used as the reference origin and the $\mathrm{X}$-axis is oriented East to West with the $\mathrm{Y}$ axis North to South

Mutual impedance between any horizontal earth return current-section to any horizontal earth return potential-section is

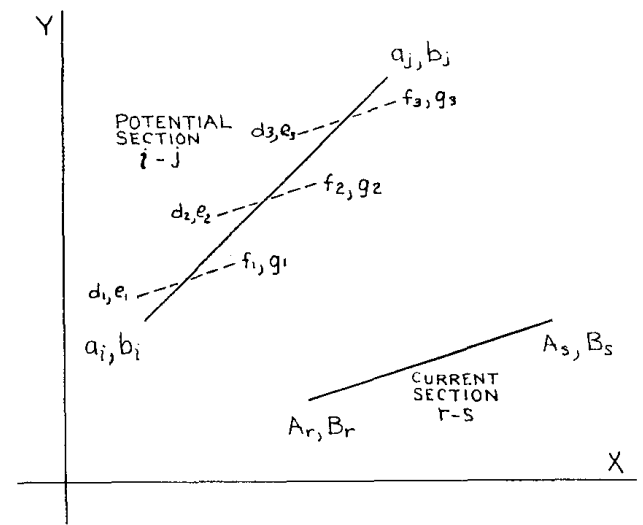

Figure A.I PARALLEL SEGMENT APPROXIMATION OF THE POTENTIALCONDUCTOR SECTION

Coordinates

Any Cur. Section r-s: (Ar, Br, hC) to (As, Bs, hC)

Any Pot. Section $\mathrm{i}-\mathrm{j}$ : $\left(\mathrm{a}_{\mathrm{j}}, \mathrm{b}_{\mathrm{j}}, \mathrm{h}_{\mathrm{p}}\right)$ to $\left(\mathrm{aj}_{\mathrm{j}}, \mathrm{bj}_{\mathrm{j}}, \mathrm{h}_{\mathrm{p}}\right) \mathrm{n}=3$

found by approximating the potential-section with equal length segments that parallel a particular current-section overall mutual impedance between all current sections to all potential sections is found by summing these segment mutuals

Segmenting the Potential Section Figure A.I shows the orientation of one section of the Current conductor and one section of the Potential conductor on the coordinate system. From the number of parallel segments that are used to approximate the Potential Section and the end coordinates of both sections it is possible to calculate the end coordinates of each parallel segment. The above example uses $\mathbf{n}=3$ or three parallel segments to approximate the Potential Section Coordinates for each parallel segment are determined with Eqs $(1.2 .3 .4)$

$d_{k}=a_{i}+\frac{k-1}{n}\left(a_{j}-a_{i}\right)-\frac{B_{s}-B_{r}}{2 n} G(i, j, r, s)$

$f_{k}=a_{i}+\frac{k}{n}\left(a_{j}-a_{i}\right)-\frac{B_{s}-B_{r}}{2 n} G(i, j, r, s)$

$e_{k}=b_{i}+\frac{k-1}{n}\left(b_{j}-b_{i}\right)-\frac{A_{S}-A_{r}}{2 n} G(i, j, r, s)$

$B k=b_{i}+\frac{k}{n}\left(b_{j}-b_{i}\right)-\frac{A_{s}-A_{r}}{2 n} G(i, j, r, s)$

$G(i, j, r, s)=\frac{\left(b_{i}-b_{i}\right)\left(A_{s}-A_{r}\right)-\left(a_{i}-a_{j}\right)\left(B_{s}-B_{r}\right)}{C_{r s}^{2}}$

$\mathrm{j}=\mathrm{i}+1$ and $\mathrm{i}=1,2,3, \ldots, \mathrm{I} \quad \mathrm{k}=1,2,3, \mathrm{n}$

$C_{r s}=\sqrt{\left(A_{s}-A_{r}\right)^{2}+\left(B_{s}-B_{r}\right)^{2}}$

When a potential section parallels a current section, only one segment is required $(n=1)$ for the potential section to determine mutual impedances between these sections. When a potential section is at right angles with a current section mutual impedance between them is zero (use $n=1$ or skip calculation). And, when a potential section has an angular orientation with a current section use $10 \leq n \leq 50$. The larger " $\mathrm{n}$ " being required for orientations less than $135^{\circ}$ and more than $45^{\circ}$

In the Fig. 1 example, $P_{1}$ to $P_{2}, P_{1}$ to $P_{4}$, and $P_{3}$ to $P_{5}$ parallel $C_{2}$ to $C_{3}$ and $C_{4}$ to $C_{5} . P_{2}$ to $P_{3}$ and $P_{4}$ to $P_{5}$ parallel $C_{5}$ to $C_{6}$. $P_{2}$ to $P_{3}$ and $P_{4}$ to $P_{5}$ are at right angles with $C_{2}$ to $C_{3}$ and $C_{4}$ to $C_{5}$. Only current sections which are at an angle with potential sections and only potential sections which are at an angle with current sections require a " $n$ " of 10 or more $\left(C_{3}\right.$ to $C_{4}, P_{3}$ to $P_{6}$ and $P_{5}$ to $\left.P_{6}\right)$. 


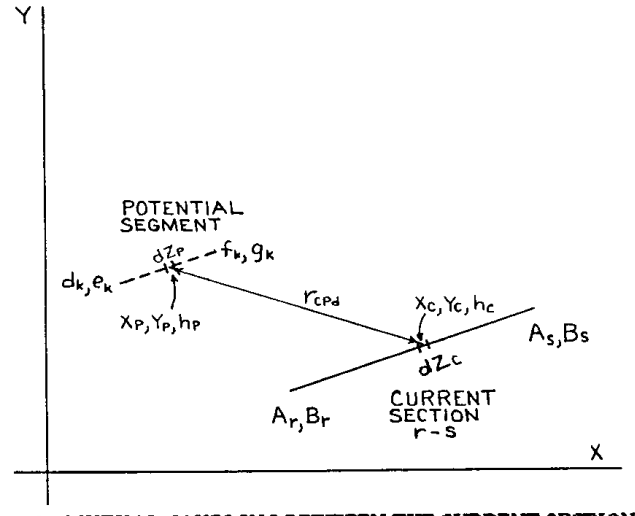

Figure A.2 MUTUAL COUPLING BET WEEN THE CURRENT SECTION AND A PARALLEL SEGMENT

$\mathrm{X}-\mathrm{Y}$ plane is at the earth surface with the positive direction of the Z-axis vertical

Current Section: (Ar, $\left.B_{r}, h_{C}\right)$ to ( $\left.A_{s}, B_{s}, h_{C}\right)$

Potential Segment: (dk, ek, hp) to $\left(f_{k}, g k, h p\right)$

The Potential Segment parallels the Current Section

Direct Mutual Coupling from a Current Conductor Section to a Parallel Potential Segment The voltage induced in the Potential Segment of Fig. A.2 due to current I in the parallel Current Section is given by the Neuman Integral [2] with the condition that the current section does not parallel the Y-axis, As * Ar

$V_{M d}=j \frac{\omega \mu_{0} I}{s z} \int_{d_{k}, e_{k}}^{f_{k, g k}} \int_{A_{r}, B_{r}}^{A_{s}, B_{S}} \frac{d Z_{C} d Z_{P}}{r_{C P d}}$

Where:

$$
\begin{array}{rlrl}
r_{C P d} & =\sqrt{\left(Z_{C}-X_{P}\right)^{2}+\left(Y_{C}-Y_{P}\right)^{2}+h_{A}^{2}} \\
h_{A} & =|h C-h P| & J & =\sqrt{-1} \\
\omega & =2 \times f, \text { fin Hz } & \mu_{0} & =4 \times / 10^{7}
\end{array}
$$

Then mutual impedance in ohms with $X, Y, Z$ coordinates in meters.

$Z_{M d}=\frac{V_{M d}}{I}=J \frac{\omega \mu_{Q}}{4 \pi} M_{d}$

$$
\begin{aligned}
& \text { and, fK.8k } A_{s}, B_{S} \\
& M_{d}=\iint \frac{d Z_{C} d Z_{P}}{\sqrt{\left(X_{C}-X_{P}\right)^{2}+\left(Y_{C}-Y_{P}\right)^{2}+h_{A}^{2}}} \\
& d_{k}, e_{k} \quad A_{r}, B_{r}
\end{aligned}
$$

This integral can be converted to $\mathrm{X}$-axis integration with the following relationships:

$$
\begin{array}{rlr}
Y_{C}=m_{r} X_{C}+k C & Y P=m_{r} X_{P}+k P \\
m_{r}=\frac{B_{S}-B_{r}}{A_{s}-A_{r}} & k P=b_{i}-m_{r} a_{i} \\
k C=B_{r}-m_{r} A_{r} & d Z_{P}=d X p \sqrt{1+m_{r}^{2}} \\
d Z C=d X_{C} \sqrt{1+m_{r}^{2}} &
\end{array}
$$

$X$-axis integration for $(7)$ is,

$$
M_{d}=\int_{d_{k}}^{\text {rk }_{k}} \int_{A_{r}}^{A_{s}} \frac{d X_{C} d X_{P}}{\sqrt{c X_{C}^{2}-b X_{C}+a}}
$$

Where:

$$
\begin{aligned}
& a=\left(1+m_{r}^{2}\right) X_{P}^{2}-2 m_{r}(k c-k p) X p+(k c-k p)^{2}+h_{A}^{2} \\
& b=2\left(X p\left(1+m_{r}^{2}\right)+m_{r}(k c-k p)\right) \\
& c=1+m_{r}^{2}
\end{aligned}
$$

Integration of (7) is completed for variable, $\mathrm{X}_{C}$ and limits $A_{S}$ and $A_{r}$ substituted. Then $a, b$ and $c$ are substituted and the resulting equation is integrated for variable $X_{p}$. Limits $f_{k}$ and $d_{k}$ are substituted and the final equation for $M_{d}$ is obtained.

$$
\begin{aligned}
M_{d}= & -\left(G_{1}+m_{r} G_{0}\right) \text { In } R_{1} \\
& +\left(G_{2}+m_{r} G_{0}\right) \text { In } R_{2} \\
& +\left(G_{3}+m_{r} G_{0}\right) \text { In } R_{3} \\
& -\left(G_{4}+m_{r} G_{0}\right) \text { In } R_{4}+s_{1}-s_{2}-s_{3}+s_{4}
\end{aligned}
$$

Where: $\quad R=$ number of Current Sections

$m_{r}=\frac{B_{s}-B_{r}}{A_{s}-A_{r}} \quad s=r+1$ and $r=1,2,3 \ldots, R$

$G_{0}=\frac{\left(B_{r}-e_{k}\right)\left(A_{S}-A_{r}\right)-\left(B_{S}-B_{r}\right)\left(A_{r}-d_{k}\right)}{C_{r s}}$

$G_{1}=\frac{A_{S}-f_{k}}{A_{s}-A_{r}} C_{r s} \quad R_{1}=G_{1}+m_{r} G_{0}+S_{1}$

$G_{2}=\frac{A_{s}-d_{k}}{A_{s}-A_{r}} C_{r s} \quad R_{2}=G_{2}+m_{r} G_{0}+S_{2}$

$G_{3}=\frac{A_{r}-f_{k}}{A_{S}-A_{r}} C_{r s} \quad R_{3}=G_{3}+m_{r} G_{0}+S_{3}$

$G_{4}=\frac{A_{r}-d_{k}}{A_{s}-A_{r}} C_{r s} \quad R_{4}=G_{4}+m_{r} G_{0}+S_{4}$

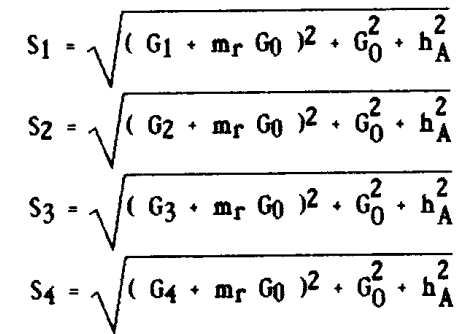

$h_{A}=|h C-h p| \quad A_{S} \neq A_{r}$

Mutual Coupling from Image to Parallel Segment In a manner similar to that used for the direct mutual, the mutual coupling to the potential segment from the current section image is determined by solving the Neuman Integral,

$V_{M_{i}}=j \frac{\omega \mu_{0} I}{4 \pi} \int_{d_{k}, e_{k}}^{f_{k}, g k} \int_{A_{r}, B_{r}}^{A_{S}, B_{S}} \frac{d Z_{C} d Z_{p}}{{ }^{r} P_{i}}$ 
Where

$$
\begin{aligned}
& r_{C P i}=\sqrt{\left(X_{C}-X_{P}\right)^{2}+\left(Y_{C}-Y_{P}\right)^{2}+I_{0}^{2}} \\
& I_{0}=\sqrt{h_{B}^{2}+2 d h_{B}-j\left(2 d^{2}+2 d h_{B}\right)} \\
& h_{B}=h C+h P \quad \quad J=\sqrt{-1} \\
& d=\frac{\sqrt{10}}{2 \pi} 10^{3} \sqrt{\frac{p}{f}}, m \quad \omega=2 \times f, \quad f \text { in } H z \\
& \mu_{0}=4 \times / 10^{7} \quad \quad p=\text { earth resistivity, } a-m
\end{aligned}
$$

Then mutual impedance in ohms with $X, Y, Z$ coordinates in meters.

$Z_{M i}=\frac{V_{M i}}{I}=J \frac{\omega \mu_{0}}{4 x} M_{i}$

and.

$M_{i}=-\left(G_{1}+m_{r} G_{0}\right) \ln X_{1}$

$+\left(G_{2}+m_{r} G_{0}\right) \ln Z_{2}$

$+\left(G_{3}+m_{r} G_{0}\right) \ln X_{3}$

$-\left(G_{4}+m_{r} G_{0}\right) \ln \mathbb{Z}_{4}+T_{1}-T_{2}-T_{3}+T_{4}$

Where: $G_{0}, G_{1}, G_{2}, G_{3}$, and $G_{4}$ are as for the direct mutual case,

$$
\begin{aligned}
& T_{1}=\sqrt{\left(G_{1}+m_{r} G_{0}\right)^{2}+G_{0}^{2}+I_{A}^{2}} \\
& T_{2}=\sqrt{\left(G_{2}+m_{r} G_{0}\right)^{2}+G_{0}^{2}+I_{A}^{2}} \\
& T_{3}=\sqrt{\left(G_{3}+m_{r} G_{0}\right)^{2}+G_{0}^{2}+I_{A}^{2}} \\
& T_{4}=\sqrt{\left(G_{4}+m_{r} G_{0}\right)^{2}+G_{0}^{2}+I_{A}^{2}} \\
& I_{0}=\sqrt{h_{B}^{2}+2 d h_{B}-j\left(2 d^{2}+2 d h_{B}\right)} \\
& \mathrm{Z}_{1}=\mathrm{G}_{1}+\mathrm{m}_{\mathrm{r}} \mathrm{G}_{0}+\mathrm{T}_{1} \quad \mathrm{Z}_{3}=\mathrm{G}_{3}+\mathrm{m}_{\mathrm{r}} \mathrm{G}_{0}+\mathrm{T}_{3} \\
& Z_{2}=G_{2}+m_{r} G_{0}+T_{2} \quad Z_{4}=G_{4}+m_{r} G_{0}+T_{4} \\
& h_{B}=h_{C}+h_{P} \quad A_{s} * A_{r}
\end{aligned}
$$

Summation of Section Mutuals Overall mutual impedance between all current sections to all potential sections is determined by the summation of these section mutuals using Eqs. ( 9 and 12):

$\mathbf{Z}_{\mathbf{C P}}=\mathbf{R}_{\mathbf{M}}+\mathbf{J} \mathbf{X}_{\mathbf{M}}$

$Z_{C P}=J \frac{\omega \mu_{0}}{i n} \sum_{r=1}^{R} \sum_{j=1}^{I} \sum_{k=1}^{n}\left(M_{d}-M_{i}\right)$

Where:

$$
\begin{aligned}
R & =\text { number of Current Sections } \quad r=1,2,3, \ldots, R \\
I & =\text { number of Potential Section } \quad \mathrm{i}=1,2,3, \ldots, \mathrm{I} \\
\mathrm{n} & =\text { number of Segments used to approximate a Potential } \\
& \text { Section and } \mathrm{k}=1,2,3, \ldots, \mathrm{n} \\
A_{S} & =A_{\mathrm{r}}
\end{aligned}
$$

\section{A.2 MUTUAL COUPLING RHEN THE CURRENT SECTION PARALLELS}

THE Y-AXIS

When a Current Section parallels the $Y$-axis $\left(A_{S}=A_{r}\right)$, formulas (9), and (12) become indeterminate. The formula for mutual coupling between this Current Section and each Potential Segment is as follows:

For Direct Mutual

$M_{d Y}=+G_{5}$ In $R_{5}-G_{6}$ ln $R_{6}-G_{7}$ ln $R_{7}$

$$
+G_{8} \ln R_{8}-S_{5}+S_{6}+S_{7}-S_{8}
$$

Where:

$G_{5}=B_{r}-\mathbf{g k} \quad R_{5}=G_{5}+S_{5}$

$\mathrm{G}_{6}=\mathrm{B}_{\mathrm{r}}-\mathrm{e}_{\mathrm{k}} \quad \mathrm{R}_{6}=\mathrm{G}_{6}+\mathrm{S}_{6}$

$\mathbf{G}_{7}=\mathrm{B}_{\mathbf{8}}-\mathbf{g k} \quad \mathrm{R}_{7}=\mathbf{G}_{7}+\mathrm{S}_{7}$

$\mathrm{G}_{8}=\mathrm{B}_{8}-\mathrm{R}_{8}=\mathrm{G}_{8}+\mathrm{S}_{8}$

$S_{5}=\sqrt{\left(B_{r}-g_{k}\right)^{2}+\left(A_{r}-d_{k}\right)^{2}+h_{A}^{2}}$

$S_{6}=\sqrt{\left(B_{r}-e_{k}\right)^{2} \cdot\left(A_{r}-d_{k}\right)^{2}+h_{A}^{2}}$

$S_{7}=\sqrt{\left(B_{s}-8 k\right)^{2}+\left(A_{r}-d_{k}\right)^{2}+h_{A}^{2}}$

$S_{8}=\sqrt{\left(B_{S}-e_{k}\right)^{2}+\left(A_{r}-d_{k}\right)^{2}+h_{A}^{2}}$

$h_{A}-\left|h_{C}-h_{P}\right| \quad A_{S}=A_{r}$

For Image Mutual

$M_{i Y}=+G_{5} \ln X_{5}-G_{6}$ in $X_{6}-G_{7} \ln X_{7}$

$$
+G_{8} \ln X_{8}-T_{5}+T_{6}+T_{7}-T_{8}
$$

$\mathrm{X}_{5}=\mathrm{G}_{5}+\mathrm{T}_{5} \quad \mathrm{Z}_{7}=\mathrm{G}_{7}+\mathrm{T}_{7}$

$\mathrm{Z}_{6}=\mathrm{G}_{6}+\mathrm{T}_{6} \quad \mathrm{Z}_{8}=\mathrm{G}_{8}+\mathrm{T}_{8}$

$T_{5}=\sqrt{\left(B_{r}-g_{k}\right)^{2}+\left(A_{r}-d_{k}\right)^{2}+I_{0}^{2}}$

$T_{6}=\sqrt{\left(B_{r}-e_{k}\right)^{2}+\left(A_{r}-d_{k}\right)^{2}+I_{0}^{2}}$

$T_{7}=\sqrt{\left(B_{s}-g_{k}\right)^{2}+\left(A_{r}-d_{k}\right)^{2}+I_{0}^{2}}$

$T_{8}=\sqrt{\left(B_{S}-e_{k}\right)^{2}+\left(A_{r}-d_{K}\right)^{2}+I_{0}^{2}}$

$I_{0}=\sqrt{h_{B}^{2}+2 d h_{B}-j\left(2 d^{2}+2 d h_{B}\right)}$

$h \mathrm{~h}=\mathrm{hC}+\mathrm{hP}_{\mathrm{P}} \quad$ "d" as before

For $d_{k}, f_{k}, f_{k}$ and $g k$ see Eqs. $(1,2,3,4)$

Summation of Section Mutuals Then using Eqs. (15 and 16) mutua from a Current Section that parallels the $Y$-axis to all Potential Sections:

$\mathbf{Z}_{C P}=\mathbf{R}_{\mathbf{M Y}}+J \mathbf{X}_{\mathbf{M Y}}$ 


$$
Z_{C P}=j \frac{\omega \mu_{0}}{4 z} \sum_{i=1}^{I} \sum_{k=1}^{n}\left(M_{d Y}-M_{i Y}\right)
$$

Where:

$$
\begin{aligned}
& I=\text { number of Potential Section } \quad i=1,2,3, \ldots ., I \\
& \mathrm{D}=\text { number of Segments used to approximate a Potential }
\end{aligned}
$$
$A_{s}=A_{r}$

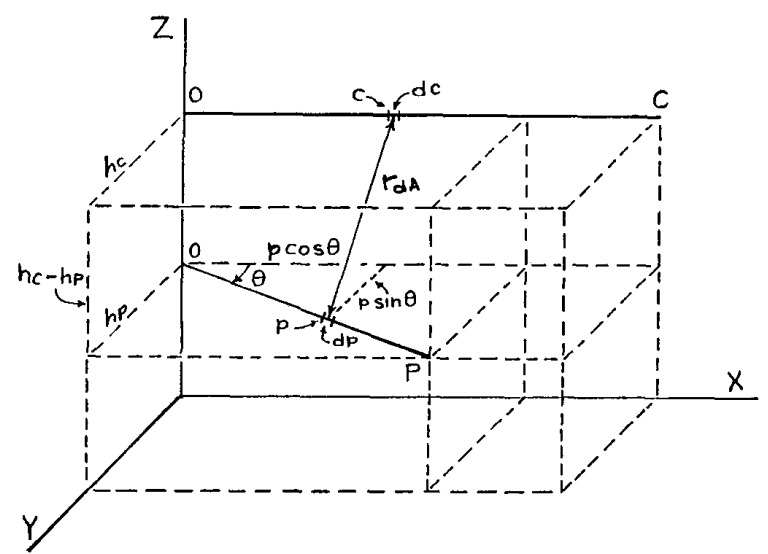

Figure A 3 MUTUAL COUPLING BETWEEN HORIZONTAL EARTH RETURN ANGLED CONDUCTORS

\section{A.3 MUTUAL COUPLING BET TEEN HORIZONTAL EARTH RETURN} ANGLED CONDUCTORS

Mutual coupling between horizontal earth return angled conductors was determined in $[1]$ by using the parallel segmented method of approximating the potential conductor. A closed form formula for the angled conductor mutual can be derived by solving the Neuman Integral. In Fig. A.3 conductor $P$ is at angle $\theta$ with conductor $C$ which is conducting current, $I$. The voltage directly induced in $\mathrm{P}$ by current $\mathrm{I}$ in $\mathrm{C}$ is given by the Neuman Integral [2]

$$
V_{A M d}=J \frac{\omega \mu_{0} I}{4 \pi} \cos \theta \int_{0}^{p} \int_{0}^{C} \frac{d c d p}{r_{d A}}
$$

Where:

$$
\begin{aligned}
& r_{d A}=\sqrt{c^{2}+p^{2}-2 c p \cos \theta+h A^{2}} \\
& h_{A}=|h C-h P| \\
& \omega=2 \times \mathrm{f}, \quad \mathrm{f} \text { in } \mathrm{Hz} \\
& \theta=\text { Horizontal Angle between } C \text { and } P \\
& \mu_{0}=4 \times / 10^{7}
\end{aligned}
$$

Direct. Angled Mutual The direct angled mutual impedance in ohms with $C$ and $P$ in moters.

$Z_{\text {AMd }}=\frac{V_{\text {AMd }}}{1}=j \frac{\omega \mu_{0} \cos \theta}{4 \mathrm{I}} \mathrm{M}_{\text {Ad }}$

And.

$$
M_{A d}=\int_{0}^{P} \int_{0}^{C} \frac{d c d p}{\sqrt{c^{2}+p^{2}-2 c p \cos \theta+h_{A}^{2}}}
$$

The integral solution from Grover [2] is modified by $\tan h^{-1} A=\frac{1}{2} \ln \frac{1+A}{1-A}$ and changing symbols to $C, P, h_{A}$ and $\theta$ is,

$$
\begin{aligned}
M_{A d}=C \ln \frac{D_{1}+D_{2}+P}{D_{1}+D_{2}-P}+P \ln \frac{D_{1}+D_{2}+C}{D_{1}+D_{2}-C} \\
+\frac{h_{A}}{\sin \theta}\left[-\tan ^{-1} \frac{\cos \theta}{\sin \theta}+\tan ^{-1} \frac{h_{A} \cos \theta}{D_{2} \sin \theta}\right. \\
+\tan ^{-1} \frac{h_{A} \cos \theta}{D_{3} \sin \theta} \\
\left.-\tan ^{-1} \frac{h_{A}^{2} \cos \theta+C P \sin ^{2} \theta}{D_{1} h_{A} \sin \theta}\right]
\end{aligned}
$$

Where:

$$
\begin{aligned}
& D_{1}=\sqrt{c^{2}+p^{2}-2 c p \cos \theta+h A^{2}} \\
& D_{2}=\sqrt{c^{2}+h_{A}^{2}} \quad D_{3}=\sqrt{p^{2}+h_{A}^{2}} \\
& h_{A}=\left|h_{C}-h_{P}\right| \quad \tan ^{-1}=\operatorname{arctangent}
\end{aligned}
$$

Image Angled Mutual With procedures similar to those used for the direct angled, mutual coupling from the current Image Conductor.

$$
\begin{aligned}
& Z_{A M i}= J \frac{\omega \mu_{0} \cos \theta}{4 I} M_{A i} \\
& M_{A i}= C \ln \frac{I_{1}+I_{2}+P}{I_{1}+I_{2}-P}+P I n \frac{I_{1}+I_{2}+C}{I_{1}+I_{2}-C} \\
&+\frac{I_{0}}{\sin \theta} \mid-\tan ^{-1} \frac{\cos \theta}{\sin \theta}+\tan ^{-1} \frac{I_{0} \cos \theta}{I_{2} \sin \theta} \\
&+\tan ^{-1} \frac{I_{0} \cos \theta}{I_{3} \sin \theta} \\
&\left.\quad-\tan ^{-1} \frac{I_{0}^{2} \cos \theta+C P \sin ^{2} \theta}{I_{1} I_{0} \sin \theta}\right]
\end{aligned}
$$

Where:

$$
\begin{aligned}
& I_{1}=\sqrt{c^{2}+p^{2}-2 c P \cos \theta+I_{0}^{2}} \\
& I_{2}=\sqrt{c^{2}+I_{0}^{2}} \\
& I_{3}=\sqrt{\mathrm{p}^{2}+\mathrm{I}_{0}^{2}} \\
& I_{0}=\sqrt{h_{B}^{2}+2 d h_{B}-j\left(2 d^{2}+2 d h_{B}\right)} \\
& h_{B}=h_{C} \cdot h p \quad d=\frac{\sqrt{10}}{2 x} 10^{3} \sqrt{\frac{p}{f}}
\end{aligned}
$$

Total Angled Mutual Impedance Total Mutual Impedance Between Angled Conductors using Eqs. (22) and (24)

$$
\begin{aligned}
& Z_{A M}=j \frac{\omega \mu_{0} \cos \theta}{4 I}\left(M_{A d}-M_{A i}\right) \\
& \omega=2 \times f, \quad f \mathrm{in} \mathrm{Hz} \quad \mu_{0}=4 \pi / 10^{7} \\
& 0^{\circ}<\theta<180^{\circ}
\end{aligned}
$$

\section{A.4 MUTUAL COUPLING BETWEEN VERTICAL CONDUCTORS}

Mutual coupling between vertical conductors is usually negligible in comparison with mutual coupling between horizontal earth return conductors. In the Fig. 1 example there is no vertical mutual coupling as the potential conductor is laying on earth. In 


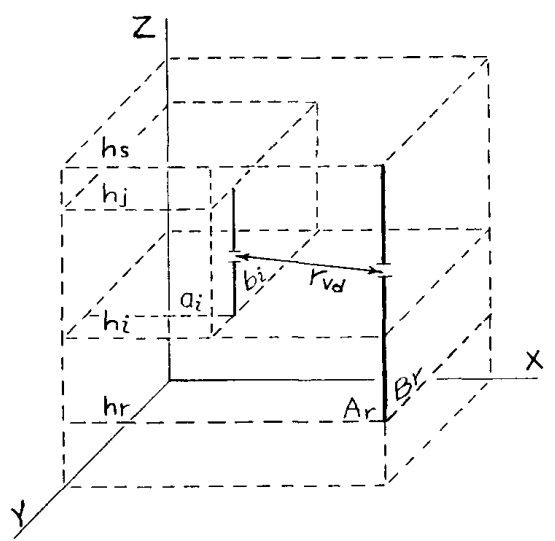

Figure A.4 MUTUAL COUPLING BETWEEN VERTICAL CONDUCTORS

Coordinates:

CUR: $A_{r}, B_{r}, h_{r}$ to $A_{r}, B_{r} h_{s}$

POT: $a_{1}$, bi $b_{1}$ to $a_{1}$, bi $b_{1}$

Fig. A 5 mutual coupling between two $15 \mathrm{~m}$ vertical conductors is shown for separations of 5 to $200 \mathrm{~m}$. Both the resistive and reactive components could be neglected for impedance measurements.

Mutual coupling between the vertical conductors of Fig. A.4 as derived with the Neuman Integral results in the following mutual impedance equations:

Direct Vertical Mutual

$Z_{V d}=\int \frac{\omega \mu_{0}}{4 \pi} \quad M V d$

$M V_{d}=-h_{1} \ln W_{1}+h_{2} \ln W_{2}$

$+h_{3} \ln W_{3}-h_{4} \ln W_{4}$

$+v_{1}-v_{2}-v_{3}+v_{4}$

Where:

$W_{1}=h_{1}+V_{1}$

$\nabla_{2}=h_{2}+V_{2}$

$h_{1}=h_{s}-h_{j}$

$w_{3}=h_{3}+v_{3}$

$h_{2}=h_{\mathbf{S}}-h_{i}$

$\nabla_{4}=h_{4}+V_{4}$

$h_{3}=h_{r}-h_{j}$

$v_{1}=\sqrt{h_{1}^{2}+\left(A_{r}-a_{j}\right)^{2}+\left(B_{r}-b_{i}\right)^{2}}$

$V 2=\sqrt{h_{2}^{2}+\left(A_{r}-a_{i}\right)^{2}+\left(B_{r}-b_{i}\right)^{2}}$

$v_{3}=\sqrt{b_{3}^{2}+\left(A_{r}-a_{i}\right)^{2}+\left(B_{r}-b_{i}\right)^{2}}$

$V_{4}=\sqrt{h_{4}^{2}+\left(A_{r}-a_{i}\right)^{2}+\left(B_{r}-b_{i}\right)^{2}}$

$\omega=2 \pi f, \quad f$ in $\mathrm{Hz}$

$\mu_{0}=4 \pi / 10^{7}$

Image Vertical Mutual

$\mathrm{ZVi}_{\mathrm{Vi}}=\mathrm{J} \frac{\omega \mu_{0}}{4} \mathrm{MVi}$

$M_{V i}=+h_{5} \ln W_{5}-h_{6} \ln W_{6}$

$-h_{7}$ ln $W_{7}+h_{8}$ ln $W_{8}$

$-V_{5}+v_{6}+v_{7}-v_{8}$

$+(d-J d) \ln \left(\frac{W_{5}}{W_{6}} \frac{W_{8}}{W_{7}}\right)$

Where:

$$
=h_{5}+d-J d+v_{5} \quad h_{5}=h_{5}-h_{j}
$$

$$
\begin{aligned}
& \mathbb{W}_{6}=h_{6}+d-1 d+V_{6} \quad h_{6}=h_{s}-h_{i} \quad B_{5}=B_{5} \\
& W_{7}=h_{7}+d-J d+V_{7} \quad h_{7}=h_{r}-h_{j} \quad a_{j}=a_{i} \\
& W_{8}=h_{8}+d-J d+v_{8} \quad h_{8}=h_{r}-h_{i} \quad b_{j}=b_{i} \\
& V_{5}=\sqrt{U_{5}^{2}+\left(A_{r}-a_{i}\right)^{2}+\left(B_{r}-b_{i}\right)^{2}} \\
& V_{6}=\sqrt{U_{6}^{2}+\left(A_{r}-a_{i}\right)^{2}+\left(B_{r}-b_{i}\right)^{2}} \\
& \mathrm{~V}_{7}=\sqrt{U_{7}^{2}+\left(A_{r}-a_{i}\right)^{2}+\left(B_{r}-b_{i}\right)^{2}} \\
& \mathrm{~V}_{8}=\sqrt{\mathrm{U}_{8}^{2}+\left(\mathrm{A}_{\mathrm{r}}-\mathrm{a}_{\mathrm{i}}\right)^{2}+\left(\mathrm{B}_{\mathrm{r}}-\mathrm{b}_{\mathrm{i}}\right)^{2}} \\
& U_{5}{ }^{2}=h_{5}^{2}+2 d h_{5}-J\left(2 d^{2}+2 d h_{5}\right) \\
& \mathrm{U}_{6}^{2}=\mathrm{h}_{6}^{2}+2 \mathrm{~d} \mathrm{~h}_{6}-J\left(2 \mathrm{~d}^{2}+2 \mathrm{~d} \mathrm{~h}_{6}\right) \\
& \mathrm{U}_{7}^{2}=\mathrm{h}_{7}^{2}+2 \mathrm{~d} \mathrm{~h}_{7}-\mathrm{J}\left(2 \mathrm{~d}^{2}+2 \mathrm{~d} \mathrm{~h}_{7}\right) \\
& \mathrm{U}_{8}{ }^{2}=\mathrm{h}_{8}^{2}+2 \mathrm{~d} \mathrm{~h}_{8}-\mathrm{J}\left(2 \mathrm{~d}^{2}+2 \mathrm{~d} \mathrm{~h}_{8}\right) \\
& \omega=2 \times f . \quad \mathrm{f} \text { in Hz } \\
& d=\frac{\sqrt{10}}{2 a} 10^{3} \sqrt{\frac{p}{f}} \\
& \mu_{0}=4 \pi / 10^{7} \\
& p \text { in } \Omega-m
\end{aligned}
$$

Overall Vertical Mutual from Eqs. (27) and (29)

$$
Z_{V}=\int \frac{\omega \mu_{0}}{4 \pi}(M V d-M V i)
$$

$$
\omega=2 \times f, \text { f in } \mathrm{Hz} \quad \mu_{0}=4 \times / 10^{7}
$$
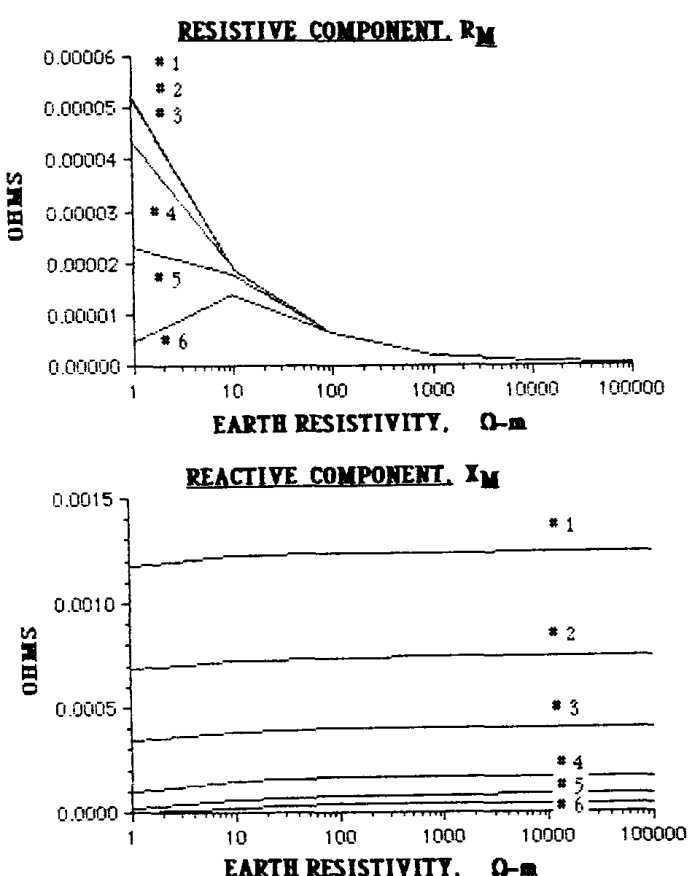

Figure A 5 MUTUAL COUPLING BET WEEN LINE CONNECTIONS AT THE SUBSTATION DEAD-ENDTOWER

\begin{tabular}{llll}
\multicolumn{1}{l}{ Spacing: } & $f=60 \mathrm{~Hz}$ & $h_{S}=h_{j}=15 \mathrm{~m}$ \\
$* 1=5 \mathrm{~m}$ & $\# 3=20 \mathrm{~m}$ & & $* 5=100 \mathrm{~m}$ \\
$* 2=10 \mathrm{~m}$ & $* 4=50 \mathrm{~m}$ & & $* 6=200 \mathrm{~m}$
\end{tabular}


Discussion

Jacques Fortin (Hydro-Quebec): The author's paper extends the understanding and application of formulas for determining mutual impedance between diversely routed earth return conductors used to measure grounding grid impedance. As the grounding impedance measurement could be in error from mutual coupling, current test conductor to potential test conductor, correction of measured impedance may be required. Additional measurement errors can be introduced in the potential conductor by mutual coupling from current flow in overhead neutrals, buried neutrals, overhead ground wires (that are bounded to the substation ground grid and towers), water piping (that connect to the neutral conductors), and buried bare shield conductors, such as contained in urban areas. Are the author's methods applicable to these situations?

On page three of the paper the authors list conditions requiring segmentation of the potential sections. Would the authors indicate the tests used to determine if a potential section is parallel at right angles or angular with a current section? At the end of the page, do the list of angles sections requiring a " $n$ " of 10 or more should be: $\left(\mathrm{C}_{2} \mathrm{C}_{3}, \mathrm{P}_{3} \mathrm{P}_{6}, \mathrm{P}_{5} \mathrm{P}_{6}\right),\left(\mathrm{C}_{3} \mathrm{C}_{4}, \mathrm{P}_{1} \mathrm{P}_{2}\right.$, $\left.\mathrm{P}_{1} \mathrm{P}_{4}, \mathrm{P}_{2} \mathrm{P}_{3}, \mathrm{P}_{4} \mathrm{P}_{5}, \mathrm{P}_{3} \mathrm{P}_{5}, \mathrm{P}_{5} \mathrm{P}_{6}, \mathrm{P}_{3} \mathrm{P}_{6}\right),\left(\mathrm{C}_{4} \mathrm{C}_{5}, \mathrm{P}_{3} \mathrm{P}_{6}, \mathrm{P}_{5} \mathrm{P}_{6}\right),\left(\mathrm{C}_{5} \mathrm{C}_{6}, \mathrm{P}_{3} \mathrm{P}_{6}, \mathrm{P}_{5} \mathrm{P}_{6}\right)$ ? Is there any advantage to selecting the coordinate system orientation so as to parallel either a current or potential section?

At the meeting the authors presented a comparison between ANSI/IEEE Standard 367-1987 and the Segmented Methods of the paper to calculated mutual impedance between a power line and a telephone line given in the standard. This material is of general interest and would be a valuable addition to the paper.

Manuscript received March 1, 1990.

\section{CLOSURE}

E.J. ROGERS AND JF. WHITE The authors appreciate the comments. questions, and interest of the discusser

$\mathrm{Mr}$. Fortin has raised the very practical problem of errors introduced in the measurement of grounding potential rise by test current flowing in grounding conductors extending externally from the grid. Mutual impedance formulas require the exact knowledge of conductor routing relative to the potential conductor and the current distribution in these conductors. In urban areas that contain water piping. distribution neutrals and buried shield conductors, all tied to the grid it is unlikely that these requirements can be entirely satisfied. Grounding measurement in these urban cases will require special procedures such as: current distribution measurements. potential conductor routing so as to minimize this mutual coupling. step and touch measurements near external circuits that conduct significant portions of the fault current to earth, and locating the remote potential electrode $30 \mathrm{~m}$ or more from these external earth return circuits In the case of the overhead ground wire bonded to grids and towers. it is possible to make mutual corrections Line sections, in this paper are defined as the straight portions of the line that do not change direction.

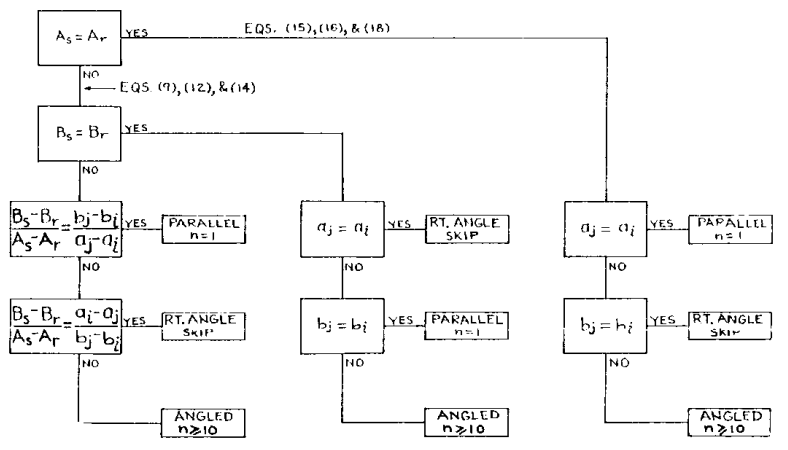

Figure C-1 TESTS TO DETERMINE A POTENTIAL SECTION ORIENTATION WITH A CURRENT SECTION
Fig. C-1 summarizes condition tests used to determine whether a potential section parallels, is at right angles, or angular with the current section. The authors are in-agreement with the list of angled sections of Fig. 1 requiring a " $n$ " of 10 or more.

Formulas (9, 12. and 14) for calculating mutual impedance between one current section and each potential section and the test program of Fig. $\mathrm{C}-1$ could be simplified and Formulas (15, 16, and 18) eliminated, if the coordinate system were to be oriented to agree with a current section However mutual impedance to potential sections calculated with each subsequent current section will require translation and rotation of the coordinate system axis so as to agree with each new current section. All potential section coordinates would change in each new coordinate system. $\mathrm{Mr}$ Fortin's suggestion if incorporated in a calculator program could result in fever programs steps and possibly less computation time

At the recommendation of $\mathrm{Mr}$. Fortin we are including the comparison between the Segmented Method (057) and the ANSI/IEEE Standard 367-1987 Method (367) of calculating mutual impedance due to nonuniform exposure [3]

In this example mutual impedance is calculated between a power line and telecommunication line shown in Fig. C-2. Figure C-2 is a copy of Fig 35 page 80 in Standard 367 . The telephone line is composed of 10 sections extending from $A$ to 0 and back to $P$. The power line is one straight section Afthough not stipulated in 367. for this comparison, the power line is assumed to start $500 \mathrm{~m}$ before " $A$ " and extended $500 \mathrm{~m}$ past " 0 ". With this qualification. the power line will approach the infinite line approximation. Because of additional end-effects, a shorter power line would reduce the 057 calculated mutual coupling. Further, the power line height is taken as $15 \mathrm{~m}$ and the telephone line height is taken as $75 \mathrm{~m}$ which results in a height difference of $7.5 \mathrm{~m}$, as specified by 367

The 367 method $[3]$ is based on (1). The Carson formula for mutual impedance between infinitely long conductors. (2) Uniform earth (3) Approximating an angled potential section with one or more parallel segments with their overall parallel separations equal to the average of the angled separation. (4) Neglecting end-effects of finite length conductors. Items (1) and (4) will result in higher mutual impedance component values and item (3) smaller mutual reactive component, $\mathbf{Z}_{M}$, values

The segmented method $(1)$ is based an (1). The complex plane approximation for Carson. (2). Uniform earth. (3) Accounting for the end-effects between finite length conductors using both direct and image conductors, as derived with the Neuman Integral. (4) Approximating angled potential sections with 10 or more parallel segments. (5). Conductor heights above earth are utilized in the 057 method

Figure $\mathrm{C}-3$ compares the cumulative mutual impedance between the power line and telecommunication line of Fig C-2 calculated with 367 (Refer to page $85 \mathrm{Fig} .38$ [3]) and 057 . The 057 inductive component $X_{M}$ falls below 367 up to near the line cross under point. The telecommunication line is approximated by 367 with 3 parallel segments in the $H-L$ angled section. This results in a lower estimated $Z_{M}$ and the 057 cumulative curve is above 367 after $1575 \mathrm{~m}$. With 057 all angled sections are approximated with 10 parallel segments. $R M$ calculated with 057 is well below the 367 cumulative curve.

Figured $C-4$ is the mutual impedance components, $R_{M}$ and $X_{M}$ calculated for each telecommunication line section. Fig. C-4 shows the differences between 057 and 367 . Table 1 summarizes numerical values of the mutual impedance components calculated with 057 and 367 by line sections. The largest difference in the $X_{M}$ component occurs in the G-M section near where the telecommunication line crosses under the power line. 


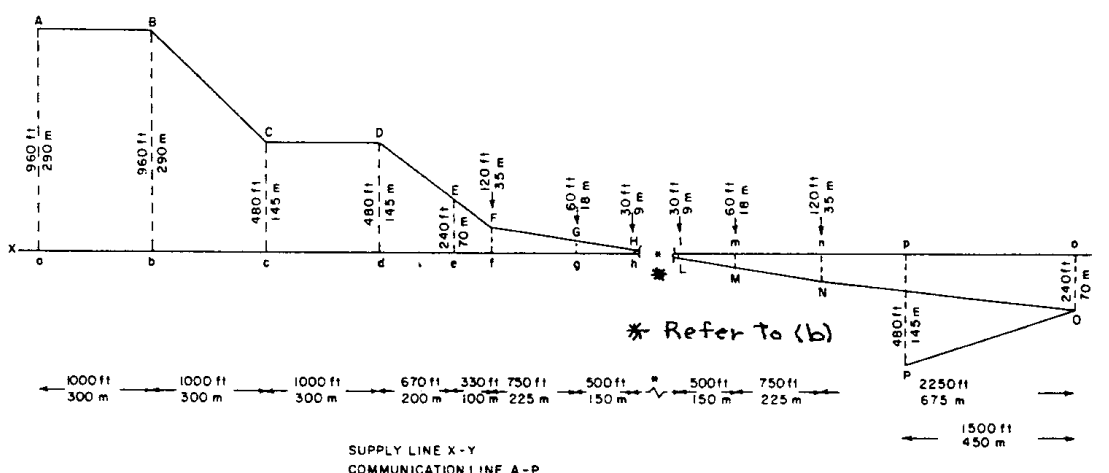

(a)

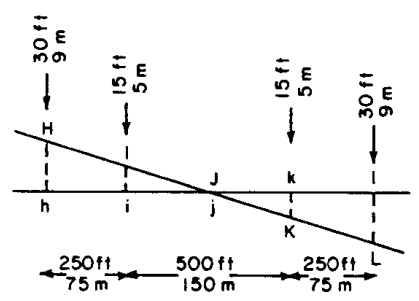

(b)

Figure C-2 NONUNIFORM EXPOSURE BETWEEN A POWER LINE AND A TELECOMMUNICATION LINE Taken from ANSI/IEEE Standard 367-1987 page 80

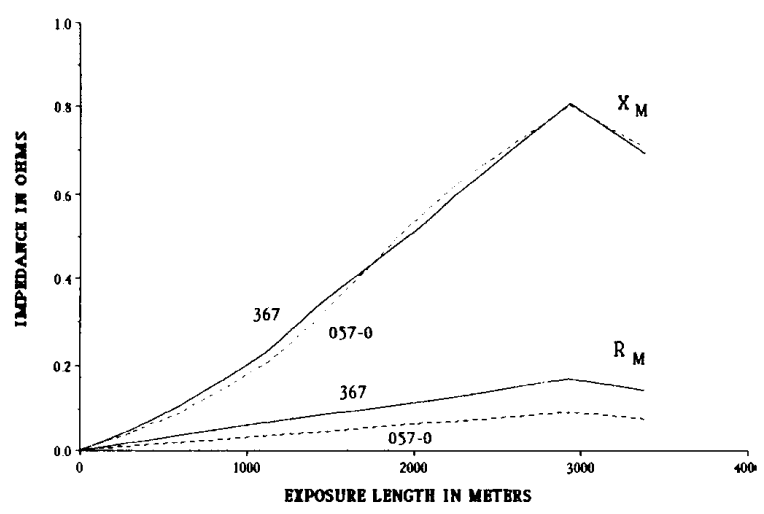

Figure C-3 CUMULATIVE MUTUAL IMPEDANCE COMPONENTS FOR EIG.C-1

$f=60 \mathrm{~Hz} \quad \rho=1000 \Omega-m \quad h C=15 \mathrm{~m} \quad h p=7.5 \mathrm{~m}$

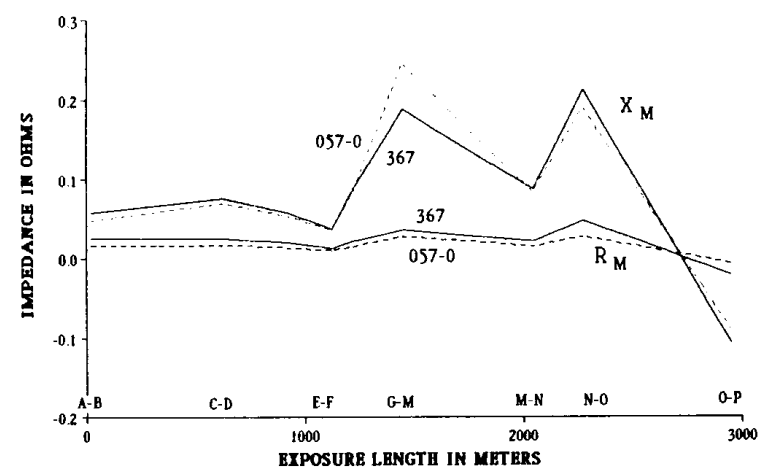

Figure C-4 MUTUAL IMPEDANCE COMPONENTS FOR EACH LINE SECTION OF FIG.C-1

$f=60 \mathrm{~Hz} \quad \rho=1000 \mathrm{n}-\mathrm{m} \quad \mathrm{hC}=15 \mathrm{~m} \quad \mathrm{hP}=7.5 \mathrm{~m}$

Figure $C-5$ shows the overall mutual coupling between the power line and the telecommunication line for earth resistivities 1 to $100,00 \mathrm{n}-\mathrm{m}$ as calculated by 057 . Earth resistivity variations along the power line could be approximated by two or more resistivity zones.
Table 1 COMPARISON OF THE MUTUAL IMPEDANCE COMPONENTS CALCULATIED BY 367 AND 057 FOR EACH LINE SECTION

$f=60 \mathrm{~Hz} \quad \mathrm{p}=1000 \mathrm{n}-\mathrm{m} \quad \mathrm{hC}=15 \mathrm{~m} \quad \mathrm{hp}=7.5 \mathrm{~m}$

\begin{tabular}{|c|c|c|c|c|c|}
\hline \multirow{2}{*}{$\begin{array}{l}\text { LINE } \\
\text { SECTION }\end{array}$} & \multirow{2}{*}{$\begin{array}{c}\text { SECTION } \\
\text { LENGTH } \\
\text { m }\end{array}$} & \multicolumn{2}{|c|}{$\mathrm{R}_{\mathrm{M}}$} & \multicolumn{2}{|c|}{$x_{M}$} \\
\hline & & 367 & $057-0$ & 367 & $057-0$ \\
\hline$A-B$ & 300 & 018 & 0085 & 050 & 041 \\
\hline $\mathrm{B}-\mathrm{C}$ & 300 & 018 & 0090 & 059 & .051 \\
\hline C-D & 300 & 018 & 0094 & 068 & 062 \\
\hline D-E & 200 & 012 & .0064 & .051 & .046 \\
\hline E-F & 100 & .006 & 0032 & 030 & .029 \\
\hline$F-G$ & 225 & .014 & .0073 & .080 & .076 \\
\hline$G-M$ & 600 & 028 & 0194 & .182 & .240 \\
\hline$M-N$ & 225 & .014 & .0071 & .080 & .075 \\
\hline $\mathrm{N}-\mathrm{O}$ & 675 & 041 & 0199 & 207 & .183 \\
\hline O-P & 450 & -.027 & -.0130 & -.114 & -.097 \\
\hline
\end{tabular}

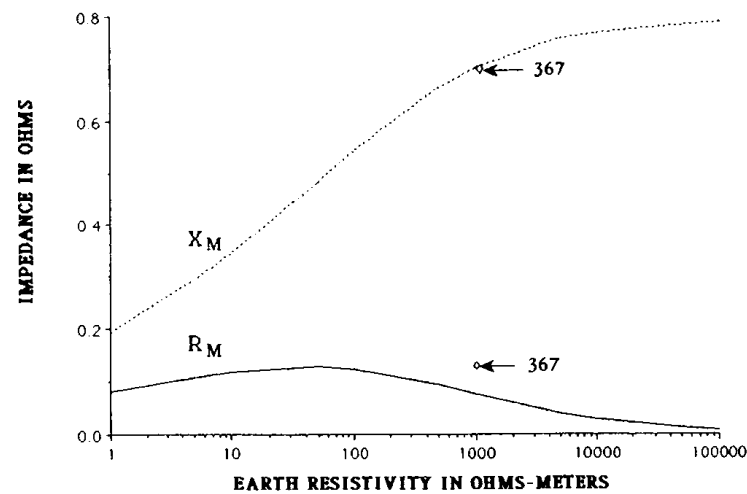

Figure C-5 OVERALL MUTUAL IMPEDANCE COMPONENTS FORFIG. C- 1 VERSUS EARTH RESISTIVITY

$\mathrm{f}=60 \mathrm{~Hz} \quad \mathrm{hC}=15 \mathrm{~m}$

$\mathrm{hp}=7.5 \mathrm{~m}$

\section{REFERENCES}

(3) ANSI/IEEE Standard 367-1987, IEEE Recommended Practice for Determining the Electric Power Station Ground Potential Rise and Induced Voltage from a Power Fault. 